\title{
Transformational leadership, innovative work behavior, and employee well-being
}

\author{
Mohammad Sadegh Sharifirad
}

Published online: 25 July 2013

(C) International Network of Business and Management 2013

\begin{abstract}
Different studies have shown that transformational leadership, which is categorized as a positive leadership, can increase employee's well-being and innovation. However, the research about the social interactional mechanism used to improve the aforementioned outcomes is scant. This research investigates the mediating roles of leader's active empathetic listening and psychological safety through a survey data collected from 583 postgraduate management students in three top universities in Iran working either full-time or part-time. After doing a series of confirmatory factor analyses, this study employed structural equation modeling to test the hypotheses of the proposed model. Results of the analyses revealed that leader's active empathetic listening and psychological safety fully mediated the influence of TL on innovative work behavior, and partially mediated the influence of TL on employee well-being. This paper contributes in three ways. First, it investigates the mediating roles of leader's active empathetic listening and psychological safety as two interpersonal factors on innovative work behavior and employee well-being. Second, findings of the study make contributions to the body of research in a number of related disciplines, such as transformational leadership, employee well-being, and innovative work behavior. Third, this paper highlights the significant impact of listening as a taken-for-granted aspect of interactions in leader-follower relationship. Implications of the findings for research and practice are discussed.
\end{abstract}

Keywords Transformational leadership · Active empathetic listening · Innovative work behavior · Psychological safety · Employee well-being

\footnotetext{
M. S. Sharifirad ( ()

Faculty of Economic and Administrative Sciences, Ferdowsi University of Mashhad, Mashhad, Iran e-mail: ili_teacher@yahoo.com
} 


\section{Introduction}

Employee wellbeing has recently attracted much attention of researchers, not only for the sake of happier and productive employees (Wright and Staw 1999), but also to mitigate the negative effects of stress in the workplace such as frustration, depression, anxiety, and many physical problems, including cardiovascular diseases and high blood pressure among individuals (e.g., Siu et al. 2007). Some employers in Western societies have taken increasing interest in enhancing and maintaining employee well-being, and some employees are even willing to take pay-cuts in order to be healthier and happier (Warr 1999).

Previously-published research has proved that employee well-being is affected both by the physical work environment and the psychological work environment (e.g., Gilbreath and Benson 2004). As summarized by Sparks et al. (2001), management style is one of the four main psychosocial work environment issues that is one of current concerns for employee well-being and occupational health in the 21 st-century workplace (Liu et al. 2010). The focus has been on supervisors because they can be a major influence, positive or negative, on employees' work lives because supervisors have a large impact on work demands, control, and social support (e.g., Gilbreath and Benson 2004; Harris and Kacmar 2006). It is argued that positive leadership, which comprises positive attitudes of passion, skills, and confidence to inspire followers, has the potential to elevate followers in the long term in areas such as trust, commitment, and well-being (Liu et al. 2010). The closest leadership style to positive leadership is transformational leadership (TL), since Bass (1985) considered leader's motivational and elevating effect on followers as the core of his definition.

The close link between innovation and performance has caused enthusiasm to understand factors shaping innovation. A review by Mumford et al. (2002) mentions a broad range of factors including strategy, structure, climate practices, group interactions and individual performance capabilities. More recently, various authors have specifically highlighted the impact of leadership on creative efforts and innovation (Mumford et al. 2002; Jung et al. 2003; Mumford and Licuanan 2004). Within the strand of research concerned with the relationship between leadership and the innovation process, transformational leadership is especially interesting, as theory suggests that transformational leaders can enhance innovative work behavior (Bass and Avolio 1990; Sosik et al. 1998). Bass (1985) defined a transformational leader as one who motivates followers to do more than they are originally expected to do. Despite theoretical reasoning, little empirical evidence exists to confirm the relationship between leadership, innovative work behavior, and the socio-psychological mechanism in between, inspiring the need for further investigation (Reuvers et al. 2008).

Confirming positive leadership thesis, researchers have established associations between TL, innovative work behavior and employee well-being based on research done in Western societies (e.g., Gong et al. 2009; Arnold et al. 2007; Densten 2005; Sivanathan et al. 2004; Seltzer et al. 1989). However, there is very little research exploring the relationship between TL and employee well-being in Eastern contexts, especially Iran, and even there is less research examining the socio-psychological mechanism of this relationship. 
Cultural dimensions can impact relationships and the outcomes such as stress. The two most impactful dimensions of national culture, in this respect, are power distance and individualism/collectivism. As an Eastern context, Iranian managers are characterized as being individualistic and high in power distance (Javidan and Dastmalchian 2003). Iranians can be quite external in their locus of control, attributing control of events to forces outside of themselves (Boyacigiller and Adler 1991; House et al. 1999). Control itself has been linked to perceptions of both job stressors and job strains (Ganster and Fusilier 1989).

Countries in which people are external tend to score high in job strains. According to Iran's economic and political position in the world, employee wellbeing is very susceptible. With the imposition of sanctions on Iran and, as a result, its struggling economy and devalued currency, organizations, employees and people have experienced much economic pressure. As a notorious example, job stress has increased among the Iranian since every crisis brings lack of stability and unpredictability which are the sources of stress (Miller 1981).

This study aims to bridge the above-mentioned gap in this knowledge by exploring the relationship between transformational leadership, employee wellbeing and innovative work behavior in three Iranian societies. Specifically, we intend to examine the roles of leaders active empathetic listening and perceived psychological safety by the follower as two links between transformational leadership and two constructs of employees' innovative work behavior and wellbeing. Several researchers have underlined the importance of pro-subordinate behaviors and positive relationships between supervisors and subordinates (Einarsen et al. 2007; Gerstner and Day 1997; Humphrey et al. 2007; Ilies et al. 2007). Nevertheless, there is little research exploring the potential of social interactions to increase or decrease employees' innovative work behavior and well-being. Aligned with this point, we use active empathetic listening and psychological safety to reflect the quality of relationships and organizational climate, respectively, and posit them as mediators between transformational leadership and two outcomes for the followers: innovative work behavior and well-being.

\section{Theory and hypotheses}

\section{Transformational leadership and employee well-being}

Wellbeing is such a broad concept that has resulted in the complexity of employee well-being construct. The definitions of well-being range from a simple one such as feeling good or feeling bad (Warr 2006) to a multi-construct one such as containing objective list, preference satisfaction and mental states (Parfit 1984). In a narrower sense, employee well-being is simply defined as "a pleasurable or positive emotional state resulting from the appraisal of one's job or job experiences" (Locke 1976). Some research has proposed that it comprises some psychological indicators such as affect, anxiety and frustration and physiological ones such as blood pressure and heart condition and general physical health (Danna and Griffin 1999). 
Leadership is an influential aspect of the work environment for employees (e.g., Oldham and Cummings 1996; Scott and Bruce 1994). Transformational leadership describes a class of behaviors enacted by a leader composed of four dimensions: intellectual stimulation (i.e., challenging the status quo and taking novel approaches to problems), charisma or idealized influence, inspirational motivation (i.e., energizing followers by articulating a compelling vision), and individualized consideration (i.e., supporting, mentoring, and developing followers) (Bass 1985).

Several studies have found that leaders' behavior affects employees' well-being. Gilbreath and Benson (2004) investigated the effect of supervisory behavior on employee well-being (conceptualized as psychiatric disturbance) using a structure versus consideration conceptualization of supervisory behavior. A recent experimental study (Bono and Ilies 2006, p. 331) focused on the effect of charismatic leaders on the mood of followers and showed that "charismatic leaders enable their followers to experience positive emotions".

To elaborate, some features of the transformational pattern have been proposed relating to employee well-being. For example, individual consideration from a transformational leader is reflected in the leader's behaviors showing concern for followers' needs and feelings (Liu et al. 2010). This kind of transformational leader behavior could be associated with favorable affective responses, such as job satisfaction (Butler et al. 1999). Inspirational motivation could increase followers' task clarity and eliminate uncertainty and ambiguity by providing a frame of reference for describing expected performance, which in turn are related to lower levels of perceived work stress and less stress symptoms (Turner et al. 2002). As early as 1990, Podsakoff et al. demonstrated that transformational leader behaviors influenced employees' job satisfaction, and this has been confirmed by Fuller et al. (1996) meta-analysis. Seltzer et al. (1989) carried out research among 277 MBA students who held full-time jobs, and found that symptoms of stress and burnout could be attributed to the lack of TL. In other words, TL can reduce subordinates' stress symptoms and job burnout. Therefore, we hypothesize that:

Hypothesis 1a Transformational leadership is positively related to employee wellbeing.

Transformational leadership and innovative work behavior

Farr and Ford (1990) define innovative work behavior (IWB) as an individual's behavior that aims to achieve the initiation and intentional introduction (within a work role, group or organization) of new and useful ideas, processes, products or procedures. IWB differs from employee creativity-the production of new and useful ideas procedures (Amabile 1988)_-because it also includes the implementation of ideas. Unlike creativity, IWB is explicitly intended to be somehow beneficial. It has a clearer applied component and is expected to result in innovative output. Creativity can be seen as a crucial component of IWB, most evident in the beginning of the innovation process when problems or performance gaps are recognized and ideas are generated in response to a perceived need for innovation (West 2002). 
Some studies, albeit few, have revealed the direct and indirect positive correlations between transformational leadership and innovation. A study by Sosik et al. (1998) used the number of creative ideas generated as a component of effectiveness. Results indicated a positive relationship between transformational leadership and creativity in a computer-mediated brainstorming exercise. In a series of studies by Wilson-Evered et al. (2001, 2004), transformational leadership was linked with innovative work climate and behaviors in health care teams. Reuvers et al. (2008) asserted that only two studies have successfully and specifically linked transformational leadership to innovative work behavior: Janssen (2002) and Wilson-Evered et al. (2001, 2004). More indirect evidence for the posited relationship is provided in a study by Jung et al. (2003). Their study examined the relationship between transformational leadership and organizational innovation in 32 Taiwanese companies in the electronics industry. Analysis yielded a direct and positive link between transformational leadership and organizational innovation. Wilson-Evered et al. (2001, 2004) work on health care teams found a positive relationship between transformational leadership and climate for innovation as well as a link between transformational leadership and morale and morale and implemented innovations. In 2008, Reuvers and his colleagues after doing research in four Australian hospitals revealed a positive and significant relationship between transformational leadership and innovative work behavior. As evidenced through the previously reviewed studies, this study conforms to the theorized relationship that transformational leadership positively influences followers' innovative work behavior (Hater and Bass 1988; Bass and Avolio 1990).

Hypothesis 1b Transformational leadership is positively related to innovative work behavior.

The mediating role of active empathetic listening

Multiple attempts have been made to define listening within the workplace environment for the purposes of enabling research on listening. Glenn (1989) found over 50 definitions and models in her review of the listening literature to that date. Along with these definitions and models, different words have attached listening to give it a more restrictive and practical nature. As two examples, active listening is much more than hearing; it requires use of the ears and the mind (Newstrom 2011); effective listening comprises of learning about the feelings and emotions of that person and sending signals to show care about employees. In 1999, Comer and Drollinger proposed a new approach toward listening by adding empathy to active listening. Although it is used in buyer-seller relations to enhance selling performance (Drollinger and Comer 2012; Comer and Drollinger 1999), the introduction of this topic in the relations between leaders and followers does not seem absurd and strange since one may consider leaders as those who are working with some people having ideas, thoughts, feelings, emotions and even complaints about their job, workplace, colleagues and so on and may try to show them to leaders to ask for the enhancement, change or preservation of the status quo. In return, it is incumbent upon leaders to 
increase enthusiasm, cooperation commitment and creativity, to say a few, through paying attention to what they own in their hearts and minds.

Active empathetic listening is the process whereby listeners receive verbal and nonverbal messages, process them cognitively, respond to them verbally and nonverbally, and attempt to assess their underlying meaning intuitively by putting themselves in the other person's place throughout. The work of Comer and Drollinger (1999) and Drollinger et al. (2006) continues to foster this stream of listening research by synthesizing listening, or particularly what they call active empathetic listening, into three dimensions of sensing - the physical receipt of the message; processing - operations in the mind of the listener that assign meaning to incoming messages; and responding - the information that the listener sends back to speakers indicating that their messages have been received correctly (Comer and Drollinger 1999). In this paper, we adopted the construct proposed by Comer and Drollinger (1999) to examine our conceptual model.

Transformational leaders show empathy in their relations with subordinates. Skinner and Spurgeon (2005) conducted a study with 96 middle and senior level health managers working for the Western Australian Health Department. They examined the relationship between health managers' self-assessed empathy, their leadership behaviors as rated by their subordinates and subordinates' personal ratings on a number of work satisfaction and related outcome measures. Empathy showed a significant positive relationship to transformational leadership. This construct encompasses behaviors such as acting in a friendly manner and supportively, listening to subordinates' problems, showing concern for their needs and feelings, consulting subordinates on important issues, and treating subordinates as equal. In terms of transformational leadership, Individualized consideration encompasses a leader's ability to give personal attention to followers, to treat each employee individually, to coach, mentor, and advice followers (Bass 1990). These are the traces of empathy permeating into the building blocks of transformational leadership.

Yukl (1998) defines consideration as leader behavior that involves concern for people and interpersonal relationships. Transformational leaders create an atmosphere in which followers are allowed to express their opinions, discuss their problems, and share ideas. Needless to say, it entails listening to subordinates to show the path. Learning culture can grow in this cultivated ambience because this type of culture is supported through the process of encouraging team members to question their assumptions, approach old problems in new ways, or reframe problems in the light of the newly integrated organization's challenges (Jung et al. 2003).

Through individualized consideration, transformational leaders deal with others as individuals; consider their individual needs, abilities; listen attentively (Bass 1997; Bass and Avolio 1994). Also, individualized consideration provides the respect necessary to support psychological safety (Shin and Zhou 2003). On the whole, using intellectual stimulation and individualized consideration, transformational leadership behaviors create a team culture that is open to diverse ideas by listening to and valuing team members' divergent views, creating open exchanges of information, and resolving conflicts effectively (Bass 1998). Finally, these leaders establish mechanisms, such as ad hoc committees, to enable subordinates to participate in strategy (Vera and Crossan 2004). 
Hypothesis 2 Transformational leadership is positively related to active empathetic listening.

There is growing evidence that an effective listening (e.g., active empathetic listening) plays a vital role in successful communication and ultimately the development of healthy working relationships (Aggarwal et al. 2005; Comer and Drollinger 1999; Ramsey and Sohi 1997). Pro-subordinate behaviors, on the other hand, are behaviors that foster the motivation, well-being, and job satisfaction of subordinates, including taking care of and supporting subordinates (e.g., listening to subordinates, attending to social relations among subordinates, giving praise when due, and showing appreciation and respect) (Einarsen et al. 2007).

Mineyama et al. (2007) empirically demonstrated that subordinates who reported that supervisors demonstrated higher levels of listening skills, as well as higher levels of a person-centered attitude - that is, an attitude — based on empathy, congruence and unconditional positive regards-demonstrated more favorable psychological stress reactions.

If we pay attention to the empathetic aspect of active listening, empathic individuals possess a pro-social orientation toward others, frequently displaying consideration (Eisenberg and Miller 1987). As a result, those high in empathy tend to develop more positive interpersonal relationships with others than those low in empathy (Batson 1987). From employees' perspectives, working for an empathic manager is more enjoyable than working for a manager who lacks empathy, eliciting higher average levels of positive affect and lower average levels of negative effect. Lobdell et al. (1993) found that poor listening diminished subordinates' individual sense of control and empowerment. Ellinger et al. (2003) found that how a supervisor listens in his or her dyadic relationships with subordinates directly equated to employee satisfaction. Hence:

Hypothesis 3a Leaders' active empathetic listening is positively related to employee well-being.

According to Dutton and Heaphy (2003), a work climate that is characterized by high-quality connections is likely to be life-enhancing and energizing and fosters human development and growth. We contend that a work context characterized by a high level of connections and psychological safety will induce a sense of vitality and energy and this state will enable individuals to lower their defenses and unleash their motivation to explore and become involved in creativity. Furthermore, a recent theoretical work (Heaphy and Dutton 2008) suggested that the physiological resourcefulness generated in positive social interactions contributes to higher levels of physiological resources for engagement in a work role. This suggests that an environment characterized by psychological safety can contribute to a sense of physical and mental strength, and this in turn will affect individuals' ability to become engaged in work behavior, and more specifically be involved in creative work.

Hypothesis 3b Leader's active empathetic listening is positively related to innovative work behavior. 
Taking Hypothesis 2 and Hypotheses $3 \mathrm{a}$ and $3 \mathrm{~b}$ together, and based on the evidence suggesting manager's support can enhance employee well-being (Sparks et al. 2001) and approachability of the manager as an important mediating factor between transformational leadership and innovative work behavior (Janssen 2002), we hypothesize that:

Hypothesis 4a Active empathetic listening is a mediator between TL and wellbeing.

Hypothesis 4b Active empathetic listening is a mediator between TL and innovative work behavior.

The mediating role of perceived psychological safety

Psychological safety refers to individuals' perceptions of the consequences of taking interpersonal risks in their work environment (Edmondson 1999, 2004). A belief that an individual is psychologically safe means that he or she feels able to show and employ his or herself without fear of negative consequences to selfimage, status, or career (Kahn 1990). In the workplace, it consists of basic beliefs about how others will respond when an individual employee chooses to act in a way that may be risky (e.g., asking a question, seeking feedback, reporting a mistake, or proposing a new idea) (Cannon and Edmondson 2001; Edmondson 2004). Edmondson (2003) argues that individuals engage in a cognitive process in which they weigh their decision whether to take a potential action or proceed in a given direction by assessing the interpersonal risk associated with that given action or behavior in the particular interpersonal work climate characterizing their organization or work group.

The relationship between supervisors and their reports has a significant positive impact on subordinates' feeling of psychological safety, and strong feelings of psychological safety have been demonstrated to have numerous positive effects in the workplace, including increasing the level of employee engagement (Kahn 1990; May et al. 2004), affecting the employee's level of vitality and creativity (Kark and Carmeli 2009), increasing the employee's ability to seek help and admit errors (Tynan 2005), enabling the ability to learn from failures (Carmeli 2007; Carmeli and Gittell 2009), strengthening the level of employee voice (Detert and Burris 2007), and further increasing productivity through greater job involvement and effort (Brown and Leigh 1996).

With the support and encouragement of transformational leaders, employees are more likely to focus on tasks rather than worries and fears (Shamir et al. 1993), thus they become willing to take risks to voice their thoughts. In 2009, Nemanich and Vera showed that there is a significantly positive relationship between transformational leadership and learning culture consisting of psychological safety (Edmondson 1999; Lipshitz et al. 2007), openness to diversity of opinions (Baker and Sinkula 1999; Hurley and Hult 1998; Tagger 2002; Woodman et al. 1993; Yang 2003), and participation in decision making (Hedberg 1981; Hurley and Hult 1998; Thompson and Kahnweiler 2002). Hence: 
Hypothesis 5 Transformational leadership is positively related to perceived psychological safety.

A psychologically safe environment gives the employees the opportunity to learn without having the anxiety of being castigated for their mistakes and risks. In a classic study on organizational change, Schein and Bennis (1965) argued that a work environment characterized by psychological safety is necessary for individuals to feel safe and be able to change their behavior. This is because psychological safety is likely to help employees overcome defensiveness and learning anxiety. For example, when individuals encounter new ideas and information that disconfirm their prior knowledge, expectations, or hopes, they may experience a sense of anxiety that will hinder their ability to learn. A sense of psychological safety is likely to enable them to overcome their anxiety and make good use of new input (Schein 1985).

Several studies suggest that psychological safety in the work environment contributes to creativity-related performance outcomes. Edmondson (1999) demonstrated that psychological safety helps teams to engage in learning behavior and argued that individuals weigh their decisions before engaging in risky actions, avoiding errors that could help the team to develop new solutions rather than maintaining the status quo. In a non-threatening climate, team members are more likely to innovate due to their lack of anxiety about negative judgments (West 1990; West and Anderson 1996; Edmondson 1999). There is evidence supporting a link between process innovation, firm performance and psychological safety at the organizational level (Baer and Frese 2003), showing that in groups larger than teams, in which collaboration is required, a feeling of safety is needed to drive the adoption and implementation of innovation. Kark and Carmeli (2009) demonstrated the existence of a relationship between psychological safety and creativity at the individual level in a study of half-time graduate students working in various industrial settings. In the most recent research Kessel et al. (2012) showed that the feeling of psychological safety in teams contributes to the teams creative performance. We therefore hypothesize that:

Hypothesis 6a Perceived psychological safety is positively related to employee well-being.

Hypothesis 6b Perceived psychological safety is positively related to innovative work behavior.

Taking Hypothesis 5 and Hypotheses $6 \mathrm{a}$ and $6 \mathrm{~b}$ together, and based on the earlier studies showing that a work environment that emphasizes positive work relationships is a central source of positive states and experiences such as satisfaction, enrichment, development, and growth (Dutton 2003; Dutton and Heaphy 2003; Quinn and Dutton 2005) we therefore hypothesize that:

Hypothesis 7a Perceived psychological safety is a mediator between TL and employee well-being.

Hypothesis $\mathbf{7 b}$ Perceived psychological safety is a mediator between TL and innovative work behavior. 


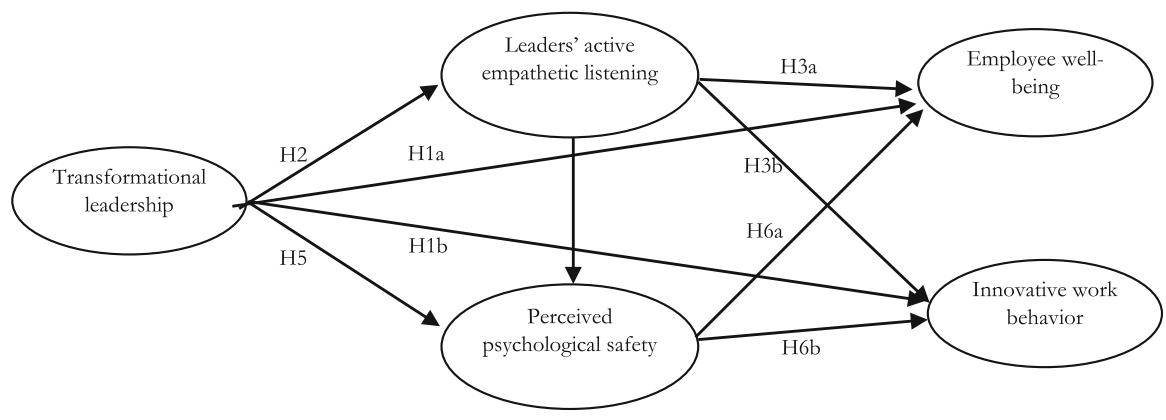

Fig. 1 The research model along with the status of the proposed hypotheses

The conceptual model of the study is shown in Fig. 1.

\section{Method}

A self-administered survey method using structured questions was adopted to gather data from students of management in Tehran, Mashhad and Kerman. All the questionnaires in which the option "I am working now" was checked were considered and others were excluded from the research. Therefore, all statistics are related to those working and studying simultaneously.

Sampling and procedures

The data collection was conducted from August to December 2012. The author organized a plan to collect data from the universities. Three days of Saturday, Tuesday, and Thursday were selected since the weekdays start from Saturday to Thursday. Most classes are held at the beginning or end of weeks to facilitate the transportation and accommodation of students living far from their hometowns. Then on each day two periods of 9-12 and 5-8 were selected to randomly select classes. Before each class, the professors of the classes were thoroughly informed about the research and the objectives. After receiving the permission, $5 \mathrm{~min}$ before the classes, the author gave brief but detailed explanations of the study to the postgraduate students of management and the confidentiality of their responses was insured. The completed questionnaires were returned immediately on site after $15 \mathrm{~min}$.

For the sample recruited in Tehran, a total of 500 questionnaires were distributed, and 380 valid questionnaires were returned, making a response rate of $76 \%$. Among the participants, $236(62 \%)$ had either a full-time or a part-time job. Participants ranged in age from 22 to 45 years with an average age of 25.45 $(\mathrm{SD}=3.87)$. They had worked, on average for 3.77 years $(\mathrm{SD}=2.59)$ within their organizations and 1.87 years $(\mathrm{SD}=2.67)$ with their current supervisors. For the sample recruited in Mashhad, a total of 460 questionnaires were distributed, and 352 valid questionnaires were returned, making a response rate of $76.5 \%$. Among the participants, $180(51 \%)$ had either a full-time or a part-time job. 
Table 1 Demographic profiles of subjects

\begin{tabular}{|c|c|c|c|c|c|c|c|}
\hline \multirow[t]{2}{*}{ Variable } & \multirow[t]{2}{*}{ Category } & \multicolumn{2}{|c|}{ Tehran } & \multicolumn{2}{|c|}{ Mashhad } & \multicolumn{2}{|c|}{ Kerman } \\
\hline & & $N$ & $\%$ & $N$ & $\%$ & $N$ & $\%$ \\
\hline \multirow[t]{2}{*}{ Gender } & Male & 151 & 64 & 101 & 56 & 104 & 62 \\
\hline & Female & 85 & 36 & 79 & 44 & 63 & 38 \\
\hline \multirow[t]{2}{*}{ Marital status } & Single & 168 & 71 & 122 & 68 & 117 & 70 \\
\hline & Married & 68 & 29 & 58 & 32 & 50 & 30 \\
\hline \multirow[t]{2}{*}{ Education } & Master & 198 & 84 & 146 & 81 & 145 & 87 \\
\hline & $\mathrm{PhD}$ & 38 & 16 & 34 & 19 & 22 & 13 \\
\hline \multirow[t]{2}{*}{ Industry } & Manufacturing & 125 & 53 & 86 & 48 & 68 & 41 \\
\hline & Service & 111 & 47 & 94 & 52 & 99 & 59 \\
\hline \multirow[t]{2}{*}{ Organizational type } & Governmental sector & 76 & 32 & 68 & 38 & 73 & 44 \\
\hline & Private-sector & 160 & 68 & 112 & 62 & 94 & 56 \\
\hline
\end{tabular}

Participants ranged in age from 21 to 36 years, with an average age of 28.25 $(\mathrm{SD}=4.47)$. They had worked, on average for 3.21 years $(\mathrm{SD}=4.50)$ within their organizations and 2.14 years $(\mathrm{SD}=2.91)$ with their current supervisors. For the sample recruited in Kerman, a total of 500 questionnaires were distributed, and 388 valid questionnaires were returned, making a response rate of $94 \%$. Among the participants, 167 (43\%) had either a full-time or a part-time job. Participants ranged in age from 21 to 42 years, with an average age of 25.61 (SD = 3.47). They had worked, on average for 2.96 years $(\mathrm{SD}=2.50)$ within their organizations and 4.35 years $(\mathrm{SD}=2.77)$ with their current supervisors. Table 1 summarizes the demographic profiles of the three samples.

\section{Measures}

All the measures were translated into Persian by forward-backward translation procedure (Brislin 1980). In order to insure that the questionnaire was not lengthy, selected items from job satisfaction, perceived work stress, and stress symptoms were used.

\section{Transformational leadership}

Since this research was done within an Iranian context, we used a questionnaire designed in an eastern context (China) with similar cultural features (Both are high in collectivism and power distance). We used Li and Shi's (2005) 26-item scale, developed for Chinese societies based on Bass's conceptualization of TL. Employees indicated the extent to which they agreed with the statements about their immediate supervisor's behaviors. Four dimensions were measured, including charisma, morale building, inspirational motivation, and individual consideration. Importantly, this scale has been widely used in Chinese societies, and its reliability and validity have been empirically demonstrated (e.g., Li et al. 2007; Wu et al. 2007). 
To evaluate the construct validity of the transformational leadership measure in the current study, we conducted a confirmatory factor analysis (CFA). Three fit indices, namely the comparative fit index (CFI), the Tucker-Lewis index (TLI) and the root-mean-square error of approximation (RMSEA), were inspected. The results of the CFA showed an acceptable fit to a four-factor model (For the Tehran sample, $\chi^{2}[155]=461.87, \mathrm{CFI}=0.94, \mathrm{TLI}=0.93, \mathrm{RMSEA}=0.06$; for the Mashhad sample $\chi^{2}[155]=513.67, \mathrm{CFI}=0.91, \mathrm{TLI}=0.90, \mathrm{RMSEA}=0.08$; for the Kerman sample, $\chi^{2}[155]=487.77, \mathrm{CFI}=0.92, \mathrm{TLI}=0.91, \mathrm{RMSEA}=0.07$ ).

Despite the fact that there are some suggestions to administer TL as a group-level variable (e.g., Purvanova et al. 2006), since the hypotheses were tested at the individual level, TL was also measured at the individual level in this study. Supporting prior studies, the four dimensions of TL were highly correlated in our data, ranging from 0.81 to 0.89 with an average correlation of 0.84 . Moreover, previously-conducted research has shown that a single higher order TL construct adequately captured the variance in the sub-dimensions of TL (e.g., Judge and Bono 2000), and that the sub-dimensions did not demonstrate discriminant validity in predicting outcomes (e.g., Bycio et al. 1995), so we combined the items to form a single TL factor. The scale had the following four subscales (26 items total) and sample items: morale building (e.g., "My immediate supervisor shares happiness and woe with his/her subordinates"); inspirational motivation (e.g., "My immediate supervisor explains to his/her subordinates the long-term meaning of their work"); individualized consideration (e.g., "My immediate supervisor would like to help his/her subordinates with their problems in life and family"); charisma (e.g., "My immediate supervisor is good at and never hesitates to take actions when dealing with tough problems"). Response options for items used a 5-point scale, ranging from 1 (strongly disagree) to 5 (strongly agree). The Cronbach's alpha of this scale was 0.94 for the Tehran Sample, 0.86 for the Mashhad sample, and 0.92 for Kerman Sample and 0.91 for the combined sample.

\section{Active empathetic listening}

The active empathetic listening scale (Drollinger et al. 2006) was chosen for this study because it embraces a listening model that has a theoretical background similar to that for psychological safety. It based its empathetic element on the therapeutic work of Rogers (1961) and his idea of unconditional positive regard. Paying attention to the nature of listening, the elements can be used for listening to everyone, although it was coined to show effective relationships between customers and salespeople. The survey encompasses three standard elements of the listening process-sensing, processing, and responding (Brownell, 1985). The scale's authors encouraged further research using the instrument outside of the sales profession to include supervisors of salespeople and other business professionals. This study continued the application of the scale in leader-follower relationship. The active empathetic listening (AEL) scale developed by Drollinger et al. (2006) was used in order to measure leaders' ability to demonstrate AEL in supervisor-subordinate interactions. The scale consisted of 21 items and internal consistency was at an acceptable level $(\alpha=0.785)$. Confirmatory factor analysis indicated a satisfactory fit (For the Tehran sample, $\chi^{2}[19]=64.94$, 
$\mathrm{CFI}=0.94, \mathrm{TLI}=0.92, \mathrm{RMSEA}=0.05$; for the Mashhad sample $\chi^{2}[19]=53.18$, $\mathrm{CFI}=0.92, \mathrm{TLI}=0.91, \mathrm{RMSEA}=0.06$; for the Kerman sample, $\chi^{2}[19]=45.11$, $\mathrm{CFI}=0.95$, TLI $=0.93$, RMSEA $=0.07)$. Response options for items used a 5 -point scale, ranging from 1 (Strongly disagree) to 5 (strongly agree). Sample items included, "My immediate supervisor keeps track of points I make" and "My immediate supervisor assures me that he or she is receptive to my ideas".

\section{Perceived psychological safety}

Five items from Edmondson's (1999) psychological safety scale adapted to this context were used to assess the extent to which respondents felt safe to speak up about issues or ideas. Examples of these items are: "Members of this organization are able to bring up problems and tough issues" and "Members of my organization are able to bring up problems and tough issues." Respondents' agreement $(1=$ strongly disagree, $5=$ strongly agree $)$ with these items formed a single scale $($ Cronbach alpha $=0.83)$.

\section{Innovative work behavior}

It was measured using ten items from innovative work behavior (IWB) designed by De Jong and den Hartog (2010). This scale has four dimensions. The dimensions with sample questions are: idea exploration (e.g., "I wonder how things can be improved"), idea generation (e.g., "I search out new working methods, techniques or instruments"), idea championing (e.g., "make important organizational members enthusiastic for innovative ideas"), and idea implementation (e.g., "contribute to the implementation of new ideas"). The results of CFA showed an acceptable fit to a one-factor model (For the Tehran sample, For the Kerman sample). A 5-point Likert scale ranging from " $1=$ never" to " $5=$ always" was used to gather data. For the four-item scale, a reliability coefficient (Cronbach's alpha) of 0.86 was obtained.

\section{Employee well-being}

To measure employee well-being, three dimensions of job satisfaction, perceived work stress, and stress symptoms were considered. For job satisfaction we used two items developed by Cammann et al. (1979) to measure job satisfaction. A sample item was, "All in all, I am satisfied with my job". The Cronbach's alpha of this scale was $0.85,0.91,0.81$, and 0.88 for the Tehran sample, Mashhad sample, Kerman sample and combined sample, respectively. To measure perceived work stress, we selected two items from prior studies (Siu et al. 2006, 2007) to measure perceived work stress. A sample item was "I usually feel that I am under a lot of pressure". The Cronbach's alpha of this scale was 0.87, 0.90, 0.90 and 0.88 for the Tehran sample, Mashhad sample, Kerman sample and combined sample, respectively. We included six items from ASSET, an organizational stress screening tool (Cartwright and Cooper 2002) to measure stress symptoms. The items were symptoms of stress- induced ill-health such as headache and constant tiredness. Each item was rated on a 5-point scale ranging from 1 (never) to 4 (frequently). 
Since well-being has three dimensions which have positive and negative natures, in this paper, work stress and stress symptoms are reversely coded to maintain the positive nature of well-being. The results of CFA showed an acceptable fit to a onefactor model (for the Tehran sample, $\chi^{2}[132]=504.45$, CFI $=0.92$, TLI $=0.90$, RMSEA $=0.06$; for the Mashhad sample $\chi^{2}$ [132] $=630.46$, CFI $=0.92$, $\mathrm{TLI}=0.91, \quad \mathrm{RMSEA}=0.07$; for the Kerman sample, $\chi^{2}[132]=445.64$, $\mathrm{CFI}=0.93$, TLI $=0.92$, RMSEA $=0.07$ ). The Cronbach's alpha of this scale was $0.87,0.87,0.90$ and 0.92 for the Tehran sample, Mashhad sample, Kerman sample and combined sample, respectively.

\section{Results}

We first conducted the data analysis on the Tehran, Mashhad and Kerman samples separately. These analyses yield similar results; therefore, we report only the results in the combined sample.

\section{Preliminary analysis}

\section{Confirmatory factor analysis}

In order to examine the distinctiveness of the study variables, we conducted CFA to compare the fit of our hypothesized measurement model to a number of nested plausible alternative models. Due to the length of transformational leadership scale, the four dimensions were used as manifest indicators ("Parceling"; Kishton and Widaman 1994) of the latent TL factor. The same strategy was also applied to the active empathetic listening scale, which was parceled as seven indicators, and each indicator included three items which were randomly selected. Table 2 presents the results of the CFA that examined the distinctiveness of the study variables. As shown in Table 2, the fit indices revealed that the hypothesized five-factor measurement model was a better fit than any alternative nested models, indicating support for the distinctiveness of the constructs in the study.

According to Joreskog (1971), the five-factor measurement model was evaluated for metric invariance across the three samples of Tehran, Mashhad and Kerman. In the unconstrained model, each indicator was allowed to load only on its factor as shown in the five-factor measurement model, but the factor loadings and covariances were allowed to vary between the three samples. With an equality constraint imposed on the factor loadings between the three samples, the constrained model was estimated and compared with the unconstrained model. An insignificant change in the Chi square statistics $\left(\Delta \chi^{2}\right)$ was considered as evidence for metric invariance given that the CFI, TLI, and RMSEA displayed an acceptable overall model fit. The fit indices revealed measurement equivalence given that both the constrained model $\left(\chi^{2}[251]=635.33\right.$, $\mathrm{CFI}=0.93, \quad$ TLI $=0.92, \quad$ RMSEA $=0.07)$ and the unconstrained model $\left(\chi^{2}\right.$ $[239]=609.57, \mathrm{CFI}=0.92, \mathrm{TLI}=0.91, \mathrm{RMSEA}=0.07)$ were acceptable, with an insignificant change in Chi square $(\Delta \chi(12)=25.76, P>0.05)$. 
Table 2 Results of contemporary factor analysis for the measures of variables studied

\begin{tabular}{|c|c|c|c|c|c|}
\hline Model & $\chi^{2}$ & df & TLI & CFI & RMSEA \\
\hline Five-factor model & 480.01 & 131 & 0.91 & 0.94 & 0.08 \\
\hline $\begin{array}{l}\text { Four-factor model 1: Innovative work behavior } \\
\text { and employee well-being combined }\end{array}$ & 806.39 & 135 & 0.86 & 0.92 & 0.11 \\
\hline $\begin{array}{l}\text { Four-factor model 2: Leaders' active empathetic } \\
\text { listening and psychological safety are } \\
\text { combined }\end{array}$ & 1082.96 & 135 & 0.77 & 0.81 & 0.15 \\
\hline $\begin{array}{l}\text { Four-factor model 3: Leaders' active empathetic } \\
\text { listening and employee well-being are } \\
\text { combined }\end{array}$ & 1228.34 & 135 & 0.65 & 0.72 & 0.23 \\
\hline $\begin{array}{l}\text { Three factor model 3: Innovative work behavior, } \\
\text { employee well-being and also leader's active } \\
\text { empathetic listening and psychological safety } \\
\text { combined }\end{array}$ & 1264.73 & 139 & 0.53 & 0.66 & 0.31 \\
\hline One-factor model & 4452.32 & 142 & 0.32 & 0.48 & 0.47 \\
\hline
\end{tabular}

TLI Tucker-Lewis index, CFI comparative fit index, RMSEA root-mean-square error of approximation

Convergent validity and internal consistency were examined by the loading paths of all dimensions, which are statistically significant if they exceed 0.50 . Table 6 (in Appendix) provides internal consistency and convergent validity of all variables analyzed in this study, including composite reliability index (CRI) and average variance extracted (AVE), calculated in order to test the composite (construct) reliability, as suggested by Škerlavaj et al. (2007). The values of CRI as well as AVE are presented for all constructs of the research model. The values exceed the thresholds ( 0.50 for AVE and 0.70 for $\mathrm{CRI})$, meaning the measuring instruments proposed are both valid and reliable.

Finally, discriminant validity is assessed with a variance-extracted test, where we compared the variance-extracted estimates for the two factors of interest with the square of the correlation between the two factors. Discriminant validity is demonstrated if the variance-extracted estimates are greater than the corresponding squared correlation (Fornell and Larcker 1981; Netermeyer et al. 1990). Table 3 shows all the variance-extracted estimates are greater than the corresponding squared correlations. Therefore, the above three tests fully support the discriminant and convergent validity of the five constructs tested in this study. Table 3 shows discriminant validity of the theoretical construct measures.

The common method variance problem should not be a concern for the interaction effect in this study because we obtained data from students/employees at different time periods. The use of similar methods to collect measures on criterion and predictor variables is not a source of spurious interactions (Aiken and West 1991; Evans 1985). In order to address possible concerns, we examined this CMV issue below (Podsakoff et al. 2003; Spector 2006). We used Harman's one-factor test to address the potential common method/source bias (Podsakoff et al. 2003). The basic assumption of this technique is that if a substantial amount of common method/source bias exists, either (a) a single-factor will emerge from the factor analysis, or (b) a general factor will account for the majority of the covariance 
Table 3 Discriminant validity of the theoretical construct measures

\begin{tabular}{llllll}
\hline Variable & 1 & 2 & 3 & 4 & 5 \\
\hline 1. Transformational leadership & $0.65^{* *}$ & 0.31 & 0.23 & 0.17 & 0.06 \\
2. Leader's active empathetic listening & 0.56 & $0.56^{* *}$ & 0.17 & 0.13 & 0.06 \\
3. Perceived psychological safety & 0.48 & 0.41 & $0.63^{* *}$ & 0.25 & 0.07 \\
4. Innovative work behavior & 0.36 & 0.36 & 0.50 & $0.62^{* *}$ & 0.08 \\
5. Employee well-being & 0.25 & 0.25 & 0.27 & 0.29 & $0.60^{* *}$ \\
\hline
\end{tabular}

Diagonal represents the average variance extracted; while above the diagonal the shared variance (squared correlations) are represented. Below the diagonal the $95 \%$ confidence interval for the estimated factor correlations is provided, $n=583$

** $P<0.01$

among the measures. Specifically, we conducted an exploratory factor analysis using a principal components extraction and a varimax rotation on the scales used in this study. Results indicated the presence of five factors with the first factor explaining only $25.35 \%$ of the variance while the five factors in the total explained $82.34 \%$ of the variance. Although this procedure did not completely rule out the possibility of same source bias, it is postulated that common method/source bias was not a serious problem in the current study. The fact that none of the fit indices for the single-factor measurement model approached acceptable levels (see Table 2) was also a strong support. Table 4 presents the means, standard deviations, and correlations among variables.

\section{Test of hypotheses}

The correlations between TL and employee well-being $(r=0.252, P<0.01)$, innovative work behavior $(r=0.365, P<0.01)$ provided preliminary evidence to support Hypotheses 1a and 1b. Supporting Hypotheses 2 and 5, TL had positive correlations with both leader's active empathetic listening $(r=0.564, P<0.01)$ and psychological safety $(r=0.481, P<0.01)$. Also, as it is evident from Table 4 , both leader's active empathetic listening and psychological safety were significantly related to the innovative work behavior and employee well-being. Thus, Hypotheses $3 \mathrm{a}$ and $3 \mathrm{~b}$ as well as $6 \mathrm{a}$ and $6 \mathrm{~b}$ were preliminarily supported.

Table 4 Means, standard deviations, and correlations among variables

\begin{tabular}{lllllll}
\hline & Mean & SD & 1 & 2 & 3 & 4 \\
\hline 1. Transformational leadership & 3.10 & 0.73 & & & & \\
2. Leader's active empathetic listening & 3.17 & 0.59 & $0.564^{* *}$ & & & \\
3. Perceived psychological safety & 3.08 & 0.54 & $0.481^{* *}$ & $0.414^{* *}$ & & \\
4. Innovative work behavior & 3.13 & 0.69 & $0.365^{* *}$ & $0.357^{* *}$ & $0.497^{* *}$ & \\
5. Employee well-being & 2.05 & 0.54 & $0.252^{* *}$ & $0.245^{* *}$ & $0.265^{* *}$ & $0.289^{* *}$ \\
\hline
\end{tabular}

$n=583, * * P<0.01$ 


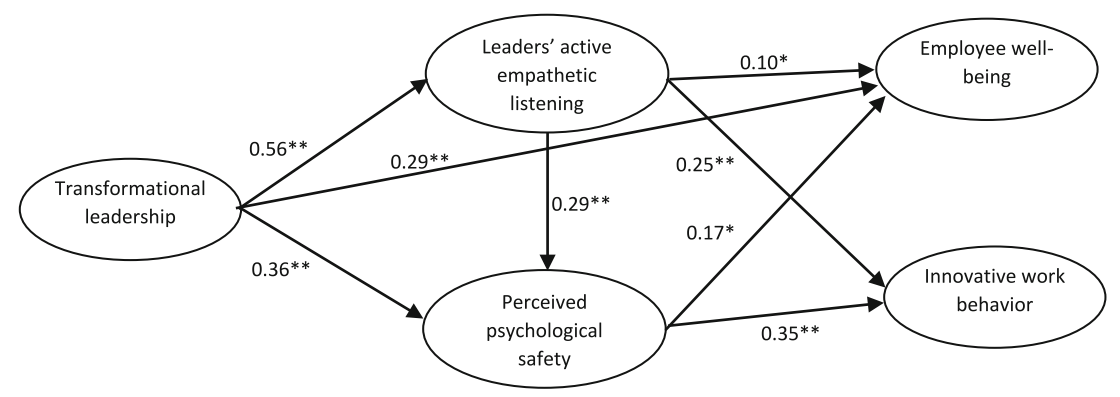

Note: The figures on the paths are the standard coefficients

Fit indexes: $\chi 2(\mathrm{df})=479.46(132) ; \mathrm{TLI}=0.92 ; \mathrm{CFI}=0.93 ; \mathrm{RMSEA}=0.07$

$\mathrm{n}=583$

$* * \rho<0.01 * *$

$* \rho<0.01$

Fig. 2 The path estimates of the final model

Hypotheses $4 \mathrm{a}$ and $4 \mathrm{~b}$ as well as $7 \mathrm{a}$ and $7 \mathrm{~b}$ were tested through a series of nested models comparison. Model 1 represents a fully mediated model. We specified paths from TL to leader's active empathetic listening and psychological safety and from both leader's active empathetic listening and psychological safety to innovative work behavior and employee well-being. All fit indices showed a good fit $\chi^{2}$ $[133]=485.48, \mathrm{CFI}=0.93, \mathrm{TLI}=0.92$, RMSEA $=0.07)$.

Based on Model 1, we drew model 2 by adding paths from TL to innovative work behavior and employee well-being. After evaluating the fit indices of the model $\left(\chi^{2}\right.$ $[131]=480.01$, CFI $=0.93$, TLI $=0.92$, RMSEA $=0.07)$, which showed a good fit, we figured out that the path from TL to innovative work behavior was not significant. So we tested model 3 based on Model 2 by deleting the direct path from TL to innovative work behavior $\left(\chi^{2}[132]=479.46, \quad\right.$ CFI $=0.93, \quad$ TLI $=0.92$, RMSEA $=0.07)$. The difference between Chi squares was significant for model 1 compared with model $3(\Delta \chi(1)=6.02, P<0.05)$. In summary, the results of model comparisons showed that Model 3 best fit our data. Table 7 in Appendix shows the comparison of the final model with alternative models. According to Fig. 2, it was obvious that Hypotheses $4 \mathrm{~b}$ and $7 \mathrm{~b}$ were fully supported. However, Hypotheses $4 \mathrm{a}$ and 7a were only partially supported, since active empathetic listening and psychological safety partially mediated the relationship between TL and employee well-being. Besides, Hypotheses 2, 3a, 3b, 5, 6a, and 6b were all fully supported. Figure two illustrates the final model and Table 5 shows the results of hypothesis testing.

\section{Discussion}

The purpose of the study was to examine the relationship between transformational leadership and two constructs of innovative work behavior and employee well-being in Iranian societies through the mediating roles of active empathetic listening and psychological safety. The results showed that transformational leadership has positive impact on employee well-being and innovative work behavior. Importantly, 
Table 5 Hypothesis testing

\begin{tabular}{|c|c|c|c|c|}
\hline Hypothesis & Structural relation (path) & $\begin{array}{l}\text { Standardized path } \\
\text { coefficient }\end{array}$ & Sig. & $t$ Value \\
\hline H1a & $\mathrm{TL} \rightarrow$ Employee well-being & 0.29 & 0.00 & 18.91 \\
\hline $\mathrm{H} 1 \mathrm{~b}$ & $\mathrm{TL} \rightarrow$ Innovative work behavior & 0.03 & 0.23 & 0.12 \\
\hline $\mathrm{H} 2$ & $\mathrm{TL} \rightarrow$ Leader's active empathetic listening & 0.56 & 0.00 & 14.97 \\
\hline $\mathrm{H} 3 \mathrm{a}$ & $\begin{array}{l}\text { Leader's active empathetic } \\
\text { listening } \rightarrow \text { Employee well-being }\end{array}$ & 0.10 & 0.02 & 8.42 \\
\hline H3B & $\begin{array}{l}\text { Leader's active empathetic } \\
\text { listening } \rightarrow \text { Innovative work behavior }\end{array}$ & 0.25 & 0.00 & 9.89 \\
\hline H5 & $\mathrm{TL} \rightarrow$ Perceived psychological safety & 0.36 & 0.00 & 23.33 \\
\hline H6а & $\begin{array}{l}\text { Perceived psychological safety } \rightarrow \text { Employee } \\
\text { well-being }\end{array}$ & 0.17 & 0.04 & 3.04 \\
\hline H6b & $\begin{array}{l}\text { Perceived psychological safety } \rightarrow \text { Innovative } \\
\text { work behavior }\end{array}$ & 0.35 & 0.00 & 8.72 \\
\hline
\end{tabular}

Fit indexes: $\chi^{2}(\mathrm{df})=479.46(132)$; TLI $=0.92 ; \mathrm{CFI}=0.93$; RMSEA $=0.07, n=583$

$T L$ transformational leadership

leader's active empathetic listening and perceived psychological safety fully mediated the relationship between transformational leadership and innovative work behavior. Also, these two mediating factors partially mediated the relationship between transformational leadership and employee well-being.

Thus, our results have confirmed the significant relationship between TL and outcomes in Iranian societies and extended the literature by illustrating the importance of leader's active empathetic listening and psychological safety in the processes from TL to employee well-being and innovative work behavior.

Based on the hypothesis regarding the effect of TL on employee well-being, our results showed that TL had both direct and indirect effects on employee well-being. In this study, the structure of employee well-being comprises job satisfaction, perceived work stress and stress symptoms. The global and broad meaning of job satisfaction which includes satisfaction with different aspects of job such as the task itself, supervisor, co-workers, pay and promotion has caused the direct and indirect relationships between transformational leadership and employee well-being. This finding supports the same result of the study done by Liu et al. (2010).

In the final model, there is no direct relationship between transformational leadership and innovative work behavior. There are mixed findings on transformational leadership and follower's creativity (Eisenbeiß and Boerner 2013). Some researchers have found positive (e.g., Shin and Zhou 2003; Gong et al. 2009), nonsignificant (e.g., Wang and Rode 2010) or even negative (Basu and Green 1997) relationships between transformational leadership and follower's innovation and creativity. In two studies done in Iran, vision and intellectual stimulation had no significant impact on innovativeness in production (Pouya et al. 2010) and the indirect effects of adaptability culture as a mediating factor was more than the direct effect of TL on innovation (Sanjaghi et al. 2011).

There are some reasons for the indirect rather than direct effect of TL on innovation. First, transformational leaders may censor follower's critical and non- 
conformal viewpoints and ideas that differ from their own, thereby triggering follower dependency and limiting innovativeness (Basu and Green 1997). Also, a change in the image of followers about leaders from those who assume responsibility and turn chaos into order to those who are idols and role models for values, beliefs, and behavioral norms (Gardner and Avolio 1998; Kark et al. 2003) can lead to a kind leadership exploiting followers by producing exceedingly high levels of emotional engagement and attachment. To support the findings of research done by Pouya et al. (2010), followers in this situation become dependent on their leader and his/her ideas, desires and visions.

High levels of power distance and individualism among Iranian managers (Javidan and Dastmalchian 2003), can lead to the centrality of self in psychosocial processes (Ghorbani et al. 2010). Self-centeredness fuels narcissistic tendencies of leaders which aggravate innovation process (Hogan et al. 1990; Kets de Vries 1988). Narcissistic leaders tend to deny their negative personal characteristics, to overestimate their abilities and to reject critical comments on their ideas or their visions (Conger and Kanungo 1998; Shamir 1991). This paper may suggest that leaders high in active empathetic listening can keep the dependency of followers in balance and cause their expressing of innovative behavior through giving opportunity to the followers to risk without any fear of the consequences. Such leaders-who are not narcissistic_-in their interactions supersede "It is ok, but..." with "It is ok and...".

\section{Implications of findings limitations and future research}

First, the results add to the knowledge of transformational leadership consequences. In most previous studies, the centrality of transformational leadership's impact on performance has been highlighted. Some researchers have labeled transformational leaders as those unjustly treat some stakeholders (top management, owners and customers) and employees because of much emphasis on task motivation and performance (Stevens et al. 1995). With the epiphany and development of positive psychology, some scholars turned their attention from performance as the only consequence of transformational leadership to other outcomes (Roberts 2006). Having the intention to fill this gap, we tried to support and add employee wellbeing and innovative work behavior as two outcomes to the range of positive outcomes associated with transformational leadership.

Second, most studies exploring the relationship between transformational leadership and employee well-being have been conducted in Western societies and the paucity of research on this relationship in Eastern countries, especially Iran, has been apparent. As a stark contrast, Iranian societies score high on individualism and power distance (Javidan and Dastmalchian 2003) in comparison with Western societies. Therefore, it seems questionable to use the constructs built in Western countries in Eastern contexts without considering cultural differences.

In two studies in Canada, Arnold et al. (2007) showed the positive effect of transformational leadership on psychological well-being. In this paper, in an Eastern context, we reached the same conclusion. Based on self-determination theory (SDT theory), psychological health and well-being are the products of motivation (Deci 
and Ryan 2008) which is the foundation of transformational leadership. Transformational leaders - consciously or unconsciously - focus on the three basic needs of human: competence, relatedness and autonomy. Based on this theory, leader's active empathetic listening, through the help of psychological safety, increases autonomous causality orientation which is positively related to psychological health and affective behavioral outcomes (Deci and Ryan 2008).

This paper also showed that apart from extrinsic factors such as incentives and money, the factors relating to the psychology of interactions between leaders and followers can positively and directly impact employees' well-being. In other words, transformational leaders, through spending time on listening to the followers empathetically, can increase emotional resources of employees and increase job satisfaction and decrease stress. This may trigger research on active empathetic listening showing its effect on decreasing follower's emotional depletion and burnout.

Third, Scholars have been studying listening from a variety of theoretical perspectives for decades (Bodie et al. 2008). Some researchers have tried to persuade sellers to listen actively and empathetically to the customers to maximize their profit (Comer and Drollinger 1999). Some have administered active listening to show the therapeutic effects of listening on patients (e.g., Ivey et al. 1968). However, there are very few, if not any, empirical studies considering listening in the relationship between leaders and subordinates. This paper has shown that active empathetic listening can be used in leader-follower communications. Also, it extends the literature of listening by addressing it as the mediating role between transformational leadership and two constructs of employee well-being and innovative work behavior.

Fourth, psychological safety has attracted increased attention primarily because it facilitates an interpersonal work context that is essential for effective learning (Edmondson 1999, 2004). In forming a psychologically safe atmosphere, the role of leaders is essential. As a proof, researchers have noted that a supportive management and context is a key antecedent of psychological safety (Carmeli and Zisu 2009; Edmondson 1999). Specific leader behaviors such as being available and accessible, inviting input, and modeling openness and fallibility, are seen to directly shape followers' perceptions of psychological safety (Edmondson 2004). This research can add active empathetic listening as a partial mediator between transformational leadership and psychological safety and highlights the impact of leader's active empathetic listening as an antecedent of psychological safety.

Last but not least, after a backward glance at results, those who are responsible for leadership development programs can figure out that transformational leadership has both direct and indirect effects on employee well-being and indirect effects on innovative work behavior. Organizations can reap benefits by providing TL training to their supervisors and managers to enhanced employees' psychological safety and increase the feeling that they are "heard", which in return enhances employee wellbeing and innovative work behavior. Actually, paying attention to Yukl's (1999) criticism that "the theory of transformational leadership would be stronger if the essential influence processes were identified more clearly," many studies have begun to focus on the processes of transformational leadership. Leadership literature 
has been filled with mediating factors relating to the follower's attitudes toward their leaders and follower's attitudes toward themselves (Piccolo and Colquitt 2006). The results of this paper corroborate these findings and disclose further underlying mechanisms.

Despite the contribution of this study, it is not without limitations. First, our data are collected from cross-sectional survey of three samples of Iranian employees who are students, too, making it difficult to draw confident causal conclusions. Also, there may be other explanations that are necessary to be explored in future research. First, in the proposed model, can transformational leadership be substituted with other kinds of leadership such as authentic leadership because of its high level of empathy and adherence to moral values and principles in decision making which may maximize benefits and minimize the psychological and physical harm to most people. Also, is there any prospect of long-lasting empathy in the listening to the followers during time? If not, what factors can challenge it and trivialize active empathetic listening in leaders' minds.

Empathic listening and active listening are relatively forgotten in leadership, because listening is not yet a clear and well-constructed interactional factor (Bodie et al. 2008). Hopefully, in the future, more outcomes of effective and constructive listening are explored, since, practically not theoretically, we have almost all witnessed the influence of mothers' active empathetic listening on reducing stress after facing a problem, getting inspired and feeling respect and identity.

Second, to conduct this research, questionnaires were distributed among management students working part-time or full-time and this may limit the generalizability of the results. First, they are management students, so their answers are influenced by their educational background; second, the questionnaires were distributed at universities and the questions were about their workplace. Their different context of answering the questions may impact their answers and make them biased. Third, the students at university may have a lot more limited feeling of being an employee whose obsession is only his job. In such a context, they may feel a higher level of satisfaction because of getting involved in learning, and educational progress. Their current educational situation may impact not only their interpretations of the constructs but also their responses to the questions.

Third, our data were collected from the same source such that the common method/source may be an issue. However, we have demonstrated that it is not a serious problem in the current study. Potential rating biases could be reduced in future studies by collecting data from different resources with different methods. In future studies, more confounding variables such as employee's performance, salary amount and having extra revenue streams need to be controlled and hence stronger findings are acquired.

Furthermore, since the current study was conducted in Iranian societies, we tried to select a questionnaire which is designed in the east and the cultural traits of the country in which it is validated are closer to those of Iran. However, future research should test the proposed model with other scales for transformational leadership such as MLQ (Bass and Avolio 1990) or Podsakoff et al.'s (1990) to test the 
similarity of results. Thinking of other types of well-being (e.g., social well-being or eudemonic) can be the outcome focus of future research in organizational contexts.

\section{Conclusion}

In spite of these limitations, the study here helps to understand two mechanisms (i.e., leader's active empathetic listening and psychological safety) through which transformational leaders may enhance employee well-being and promote creative work behavior. These findings highlight the fact that researchers and managers need to consider how transformational leaders and the interpersonal work context can foster employee well-being and innovative work behavior. Thinking about listening as a simple but effective tool can cause the unearthing of employees' internal feelings and needs; therefore, a transformational leader can capitalize upon employees' ideas and show himself as a coach and supporter at workplace.

\section{Appendix}

See Tables 6 and 7.

Table 6 Results of contemporary factor analysis for the measures of variables studied

\begin{tabular}{|c|c|c|c|c|c|c|c|}
\hline Variable & Indicator & $\begin{array}{l}\text { Factor } \\
\text { loading }\end{array}$ & $\begin{array}{l}\text { Robust } \\
t \text { value }\end{array}$ & $\begin{array}{l}\text { Loading } \\
\text { average }\end{array}$ & $\mathrm{CA}$ & CRI & AVE \\
\hline \multirow{4}{*}{$\begin{array}{l}\text { Transformational } \\
\text { leadership }\end{array}$} & Charisma & $0.86^{*}$ & 8.2 & \multirow[t]{4}{*}{0.87} & 0.91 & \multirow[t]{4}{*}{0.91} & \multirow[t]{4}{*}{0.65} \\
\hline & Morale building & $0.78 *$ & 14.4 & & 0.85 & & \\
\hline & Inspirational motivation & $0.84 *$ & 12.9 & & 0.88 & & \\
\hline & Individual consideration & $0.81 *$ & 12.7 & & 0.85 & & \\
\hline \multirow{3}{*}{$\begin{array}{l}\text { Leader's active } \\
\text { empathetic listening }\end{array}$} & Sensing & $0.88 *$ & 9.5 & \multirow[t]{3}{*}{0.85} & 0.86 & \multirow[t]{3}{*}{0.78} & \multirow[t]{3}{*}{0.56} \\
\hline & Processing & $0.78 *$ & 10.5 & & 0.78 & & \\
\hline & Responding & $0.89 *$ & 8.2 & & 0.80 & & \\
\hline $\begin{array}{l}\text { Perceived } \\
\text { psychological safety }\end{array}$ & Psychological safety & $0.84 *$ & 4.8 & 0.84 & 0.83 & 0.83 & 0.63 \\
\hline \multirow{4}{*}{$\begin{array}{l}\text { Innovative work } \\
\text { behavior }\end{array}$} & Idea exploration & $0.86^{*}$ & 5.4 & \multirow[t]{4}{*}{0.88} & 0.84 & & \multirow[t]{4}{*}{0.62} \\
\hline & Idea generation & $0.79 *$ & 9.2 & & 0.77 & & \\
\hline & Idea championing & $0.89 *$ & 11.7 & & 0.59 & & \\
\hline & Idea implementation & $0.83 *$ & 8.2 & & 0.86 & & \\
\hline \multirow[t]{3}{*}{ Employee well-being } & Job satisfaction & $0.89 *$ & 10.6 & \multirow[t]{3}{*}{0.85} & 0.87 & \multirow[t]{3}{*}{0.89} & \multirow[t]{3}{*}{0.60} \\
\hline & Perceived work stress & $0.81 *$ & 11.5 & & 0.89 & & \\
\hline & Stress symptoms & $0.86^{*}$ & 6.8 & & 0.90 & & \\
\hline
\end{tabular}

Fit indexes: $\chi^{2}(\mathrm{df})=479.46(132)$; TLI $=0.92$; $\mathrm{CFI}=0.93$; RMSEA $=0.07$

$A V E$ average variance extracted, $C A$ Cronbach's alpha, $C R I$ composite reliability index

$n=583, * P<0.01$ 
Table 7 The comparison of the final model and alternative models

\begin{tabular}{lllllllll}
\hline Structured model & $\chi^{2}$ & df & $\Delta \chi^{2}$ & Sig. & $\chi^{2} / \mathrm{df}$ & CFI & TLI & RMSEA \\
\hline Measurement model (model 3) & 479.46 & 132 & - & - & 3.63 & 0.93 & 0.92 & 0.07 \\
Model 2 & 480.01 & 131 & 0.55 & 0.18 & 3.67 & 0.93 & 0.92 & 0.07 \\
Model 1 & 485.48 & 133 & 6.02 & 0.02 & 3.65 & 0.93 & 0.92 & 0.07 \\
\hline
\end{tabular}

$T L I$ Tucker-Lewis index, $C F I$ comparative fit index, RMSEA root-mean-square error of approximation

\section{References}

Aggarwal, P., Castleberry, S. B., Ridnour, R., \& Shepherd, C. D. (2005). Salesperson empathy and listening: Impact on relationship outcomes. Journal of Marketing Theory and Practice, 13(3), 16-31.

Aiken, L. S., \& West, S. G. (1991). Multiple regression: Testing and interpreting interactions. Newbury Park, CA: Sage.

Amabile, T. M. (1988). A model of creativity and innovation in organizations. In B. M. Staw \& L. L. Cummings (Eds.), Research in organizational behavior (Vol. 10, pp. 123-167). Greenwich, CT: JAI Press.

Arnold, K. A., Turner, N., Barling, J., Kelloway, E. K., \& McKee, M. C. (2007). Transformational leadership and psychological well-being: The mediating role of meaningful work. Journal of Occupational Health Psychology, 12(3), 193-203.

Baer, M., \& Frese, M. (2003). Innovation is not enough: Climates for initiative and psychological safety, process innovations and firm performance. Journal of Organizational Behavior, 24, 45-46.

Baker, W. E., \& Sinkula, J. M. (1999). The synergistic effect of market orientation and learning orientation on organizational performance. Journal of the Academy of Marketing Science, 27(4), 411-427.

Bass, B. M. (1985). Leadership and performance beyond expectations. New York: Free Press.

Bass, B. M. (1990). Bass and Srogdill's handbook of leadership. New York: Free Press.

Bass, B. M. (1997). Does the transactional-transformational leadership paradigm transcend organizational and national boundaries? American Psychologist, 52, 130-139.

Bass, B. M. (1998). Transformational leadership: Industry, military and educational impacts. Mahwah, NJ: Erlbaum.

Bass, B. M., \& Avolio, B. J. (1990). Transformational leadership development: Manual for the Multifactor Leadership Questionnaire. Palo Alto, CA: Consulting Psychologist Press.

Bass, B. M., \& Avolio, B. J. (1994). Improving organizational effectiveness through transformational leadership. Thousand Oaks, CA: Sage.

Basu, R., \& Green, S. G. (1997). Leader-member exchange and transformational leadership: An empirical examination of innovative behaviors in leader-member dyads. Journal of Applied Social Psychology, 27, 477-499.

Batson, C. D. (1987). Pro-social motivation: Is it ever truly altruistic? In L. Berkowitz (Ed.), Advances in experimental social psychology (Vol. 20, pp. 65-122). New York: Academic Press.

Bodie, G. D., Worthington, D. L., Imhof, M., \& Cooper, L. (2008). What would a unified field of listening look like? A proposal linking past perspectives and future endeavors. International Journal of Listening, 22, 103-122. doi:10.1080/10904010802174867.

Bono, J. E., \& Ilies, R. (2006). Charisma, positive emotions, and mood contagion. The Leadership Quarterly, 17, 317-334.

Boyacigiller, N. A., \& Adler, N. J. (1991). The parochial dinosaur: Organizational science in a global context. Academy of Management Review, 16(2), 262-291.

Brislin, R. W. (1980). Translation and content analysis of oral and written material. In H. C. Triandis \& J. W. Berry (Eds.), Handbook of cross-cultural psychology (Vol. 2, pp. 389-444). Boston: Allyn and Bacon.

Brown, S. P., \& Leigh, T. W. (1996). A new look at psychological climate and its relationship to job involvement, effort, and performance. Journal of Applied Psychology, 81, 358-368.

Brownell, J. (1985). A model for listening instruction: Management applications. ABCA Bulletin, 48, 39-55. 
Butler, J., Cantrell, R., \& Flick, R. (1999). Transformational leadership behaviors, upward trust and satisfaction in self-managed work teams. Organization Development Journal, 17(1), 13-28.

Bycio, P., Hackett, R. D., \& Allen, J. S. (1995). Further assessment of Bass's (1985) conceptualization of transactional and transformational leadership. Journal of Applied Psychology, 80(4), 468-478.

Cammann, C., Fichman, M., Jenkins, D., \& Klesh, J. (1979). The Michigan organizational assessment questionnaire. Unpublished manuscript. Ann Arbor: University of Michigan.

Cannon, M. D., \& Edmondson, A. C. (2001). Confronting failure: Antecedents and consequences of shared beliefs about failure in organizational work groups. Journal of Organizational Behavior, 22, $161-177$.

Carmeli, A. (2007). Social capital, psychological safety and learning behaviors from failure in organizations. Long Range Planning, 40, 30-44.

Carmeli, A., \& Gittell, J. H. (2009). High quality relationships, psychological safety and learning from failures in work organizations. Journal of Organizational Behavior, 3, 542-567.

Carmeli, A., \& Zisu, M. (2009). The relational underpinnings of quality internal auditing in medical clinics in Israel. Social Science and Medicine, 68, 894-902.

Cartwright, S., \& Cooper, C. L. (2002). ASSET: An organizational stress screening tool. London: Robertson Cooper Limited and Cubiks.

Comer, L. B., \& Drollinger, T. (1999). Active empathetic listening and selling success: A conceptual framework. Journal of Personal Selling and Sales Management, 19, 15-29.

Conger, J. A., \& Kanungo, R. N. (1998). Charismatic leadership in organizations. Thousand Oaks, CA: Sage.

Danna, K., \& Griffin, R. W. (1999). Health and well-being in the workplace: A review and synthesis of the literature. Journal of Management, 25(3), 357-384.

De Jong, J. P. J., \& den Hartog, D. N. (2010). Measuring innovative work behavior. Creativity and Innovation Management, 19(1), 23-36.

Deci, E. L., \& Ryan, R. M. (2008). Self-Determination Theory: A macrotherapy of human motivation, development, and health. Canadian Psychology, 49, 182-185.

Densten, I. L. (2005). The relationship between visioning behaviors of leaders and follower burnout. British Journal of Management, 16(2), 105-118.

Detert, J. R., \& Burris, E. R. (2007). Leadership behavior and employee voice: Is the door really open? Academy of Management Journal, 50, 869-884.

Drollinger, T., \& Comer, L. B. (2012). Active empathetic listening as an antecedent to relationship quality and trust in a sales performance model. Journal of Business and Industrial Marketing, 28(1), 1287-1305.

Drollinger, T., Comer, L., \& Warrington, P. (2006). Development and validation of the active empathetic listening scale. Psychology and Marketing, 23, 161-180.

Dutton, J. E. (2003). Energize your workplace: How to build and sustain high-quality connections at work. San Francisco: Jossey-Bass Publishers.

Dutton, J. E., \& Heaphy, E. D. (2003). The power of high-quality relationships at work. In K. S. Cameron, J. E. Dutton, \& R. E. Quinn (Eds.), Positive organizational scholarship (pp. 263-278). San Francisco: Berrett-Koehler Publishers.

Edmondson, A. (1999). Psychological safety and learning behavior in work teams. Administrative Science Quarterly, 44, 350-383.

Edmondson, A. C. (2003). Speaking up in the operating room: How team leaders promote learning in interdisciplinary action teams. Journal of Management Studies, 40, 1419-1452.

Edmondson, A. C. (2004). Psychological safety, trust, and learning in organizations: A group-level lens. In R. M. Kramer \& K. S. Cook (Eds.), Trust and distrust in organizations: Dilemmas and approaches (pp. 239-272). New York: Russell Sage Foundation.

Einarsen, S., Aasland, M. S., \& Skogstad, M. (2007). Destructive leadership behavior: A definition and conceptual model. The Leadership Quarterly, 18(3), 207-216.

Eisenbeiß, S. A., \& Boerner, S. (2013). A double-edged sword: Transformational leadership and individual creativity. British Journal of Management, 24, 54-68.

Eisenberg, N., \& Miller, P. A. (1987). The relation of empathy to pro-social and related behaviors. Psychological Bulletin, 101, 91-119.

Ellinger, A. D., Ellinger, A. E., \& Keller, S. B. (2003). Supervisory coaching behavior, employee satisfaction, and warehouse employee performance: A dyadic perspective in the distribution industry. Human Resource Development Quarterly, 14, 435-458. 
Evans, M. G. (1985). A Monte Carlo study of the effects of correlated method variance in moderated multiple regression analysis. Organizational Behavior and Human Decision Processes, 36, 305-323.

Farr, J. L., \& Ford, C. M. (1990). Individual innovation. In M. A. West \& J. L. Farr (Eds.), Innovation and creativity at work. New York: Wiley.

Fornell, C., \& Larcker, D. F. (1981). Evaluating structural equation models with unobservable variables and measurement error. Journal of Marketing Research, 18, 39-50.

Fuller, J. B., Patterson, C. E. P., Hester, K., \& Stringer, D. Y. (1996). A quantitative review of research on charismatic leadership. Psychological Reports, 78(1), 271-287.

Ganster, D. C., \& Fusilier, M. R. (1989). Control in the workplace. In C. L. Cooper \& I. Robertson (Eds.), International review of industrial and organizational psychology 1989 (pp. 235-280). Chichester: Wiley.

Gardner, W. L., \& Avolio, B. J. (1998). The charismatic relationship: A dramaturgic perspective. Academy of Management Review, 23, 32-58.

Gerstner, C. R., \& Day, D. V. (1997). Meta-analytic review of leader-member exchange theory: Correlates and construct issues. Journal of Applied Psychology, 82, 827-844.

Ghorbani, N., Cunningham, C. J. L., \& Watson, P. J. (2010). Comparative analysis of integrative selfknowledge, mindfulness, and private self-consciousness in predicting responses to stress in Iran. International Journal of Psychology, 45, 147-154.

Gilbreath, B., \& Benson, P. G. (2004). The contribution of supervisor behavior to employee psychological well-being. Work and Stress, 18, 255-266.

Glenn, E. (1989). A content analysis of fifty definitions of listening. Journal of the International Listening Association, 3, 21-31.

Gong, Y., Huang, J., \& Farh, J. (2009). Employee learning orientation, transformational leadership, and employee creativity: The mediating role of employee creative self-efficacy. Academy of Management Journal, 52(4), 765-778.

Harris, K. J., \& Kacmar, K. M. (2006). Too much of a good thing: The curvilinear effect of leadermember exchange on stress. The Journal of Social Psychology, 146(1), 65-84.

Hater, J., \& Bass, B. M. (1988). Superiors' evaluations and subordinates' perceptions of transformational and transactional leadership. Journal of Applied Psychology, 73, 695-702.

Heaphy, E. D., \& Dutton, J. E. (2008). Positive social interactions and the human body at work: Linking organizations and physiology. Academy of Management Review, 33, 137-162.

Hedberg, B. (1981). How organizations learn and unlearn. In P. Nystrom \& W. H. Starbuck (Eds.), Handbook of organizational design (Vol. 1, pp. 3-27). New York: Oxford University Press.

Hogan, R., Raskin, R., \& Fazzini, D. (1990). The dark side of charisma. In K. E. Clark \& M. B. Clark (Eds.), Measures of leadership (pp. 343-354). West Orange, NJ: Leadership Library of America.

House, R. J., Hanges, P. J., Ruiz-Quintanilla, S. A., Dorfman, P. W., Javidan, M., Dickson, M., et al. (1999). Culture influences on leadership and organizations: Project GLOBE. Advances in Global Leadership, 1, 171-233.

Humphrey, S. E., Nahrgang, J. D., \& Morgeson, F. P. (2007). Integrating motivational, social, and contextual work design features: A meta-analytic summary and theoretical extension of the work design literature. Journal of Applied Psychology, 92, 1332-1356.

Hurley, R. F., \& Hult, G. T. M. (1998). Innovation, market orientation, and organizational learning: An integration and empirical examination. Journal of Marketing, 62, 42-54.

Ilies, R., Nahrgang, J. D., \& Morgeson, F. P. (2007). Leader-member exchange and citizenship behaviors: A meta-analysis. Journal of Applied Psychology, 92(1), 269-277.

Ivey, A., Normington, C. J., Miller, C. D., Morril, W. H., \& Haase, R. F. (1968). Micro-counseling and attending behavior: An approach to prepracticum counselor training. Journal of Counseling Psychology, 15, 1-12.

Janssen, O. (2002). Transformationeel leiderschap en innovatief werkgedrag van medewerkers: een kwestie van benaderbaarheid van de leider. Gedrag and Organisatie, 15, 275-293.

Javidan, M., \& Dastmalchian, A. (2003). Culture and leadership in Iran: The land of individual achievers, strong family ties, and powerful elite. Academy of Management Executive, 17(4), 127-142.

Joreskog, K. G. (1971). Statistical analysis of sets of congeneric tests. Psychometrika, 36, 109-133.

Judge, T. A., \& Bono, J. E. (2000). Five-factor model of personality and transformational leadership. Journal of Applied Psychology, 85(5), 751-765.

Jung, D. I., Chow, C., \& Wu, A. (2003). The role of transformational leadership in enhancing organizational innovation: Hypotheses and some preliminary findings. The Leadership Quarterly, $14,525-544$. 
Kahn, W. A. (1990). Psychological conditions of personal engagement and disengagement at work. Academy of Management Journal, 33, 692-724.

Kark, R., \& Carmeli, A. (2009). Alive and creating: The mediating role of vitality and aliveness in the relationship between psychological safety and creative work involvement. Journal of Organizational Behavior, 30, 785-804.

Kark, R., Shamir, B., \& Chen, G. (2003). The two faces of transformational leadership: Empowerment and dependency. Journal of Applied Psychology, 88, 246-255.

Kessel, M., Kratzer, J., \& Schultz, C. (2012). Psychological safety, knowledge sharing, and creative performance in healthcare teams. Journal of Creativity and Innovation Management, 12(2), $147-157$.

Kets de Vries, M. F. R. (1988). Prisoners of leadership. Human Relations, 41, 261-280.

Kishton, J. M., \& Widaman, K. F. (1994). Unidimensional versus domain representative parceling of questionnaire items: An empirical example. Educational and Psychological Measurement, 54(3), 757-765.

Li, C., \& Shi, K. (2005). The structure and measurement of transformational leadership in China. Acta Psychologica Sinica, 37(6), 803-811. (in Chinese).

Li, C., Meng, H., \& Shi, K. (2007). A comparative study on the relationship of transformational leadership, paternalistic leadership, and the PM theory with leadership effectiveness. Psychological Science, 30(6), 1477-1481. (in Chinese).

Lipshitz, R., Friedman, V. J., \& Popper, M. (2007). Demystifying organizational learning. Thousand Oaks, CA: Sage.

Liu, J., Siu, O. L., \& Shi, K. (2010). Transformational leadership and employee well-being: The mediating roles of trust in leaders and self-efficacy. Applied Psychology: An International Review, 59(3), 454-479.

Lobdell, C. L., Sonoda, K. T., \& Arnold, W. E. (1993). The influence of perceived supervisor listening behavior on employee commitment. Journal of the International Listening Association, 7, 92-110.

Locke, E. A. (1976). The nature and causes of job satisfaction. In M. D. Dunnette (Ed.), Handbook of industrial and organizational psychology (pp. 1297-1350). Chicago: Rand McNally.

May, D., Gilson, R., \& Harter, L. (2004). The psychological conditions of meaningfulness, safety and availability and the engagement of the human spirit at work. Journal of Occupational and Organizational Psychology, 77, 11-37.

Miller, S. M. (1981). Predictability and human stress: Towards a clarification of evidence and theory. In L. Berkowitz (Ed.), Advances in experimental social psychology (Vol. 14, pp. 204-254). San Diego, CA: Academic Press.

Mineyama, S., Tsutsumi, A., Takoa, S., Nishiuchi, K., \& Kawakami, N. (2007). Supervisors' attitudes and skills for active listening with regard to working conditions and psychological stress reactions among subordinate workers. Journal of Occupational Health, 49, 81-87.

Mumford, M. D., \& Licuanan, B. (2004). Leading for innovation: Conclusions, issues, and directions. The Leadership Quarterly, 15, 163-171.

Mumford, M. D., Scott, G. M., Gaddis, B., \& Strange, J. M. (2002). Leading creative people: Orchestrating expertise and relationships. The Leadership Quarterly, 13, 705-750.

Nemanich, L. A., \& Vera, D. (2009). Transformational leadership and ambidexterity in the context of an acquisition. The Leadership Quarterly, 20, 19-33.

Netermeyer, R. G., Johnston, M. W., \& Burton, S. (1990). Analysis of role conflict and role ambiguity in a structural equation framework. Journal of Applied Psychology, 75, 148-157.

Newstrom, J. W. (2011). Human Behavior at Work (13th ed.). New York: McGraw Hill.

Oldham, G. R., \& Cummings, A. (1996). Employee creativity: Personal and contextual factors at work. Academy of Management Journal, 39, 607-634.

Parfit, D. (1984). Reasons and persons. Oxford: Oxford University Press.

Piccolo, R. F., \& Colquitt, J. A. (2006). Transformational leadership and job behaviors: The mediating role of core job characteristics. Academy of Management Journal, 49, 327-340.

Podsakoff, P. M., MacKenzie, S. B., Moorman, R. H., \& Fetter, R. (1990). Transformational leader behaviors and their effects on followers' trust in leader, satisfaction, and organizational citizenship behaviors. The Leadership Quarterly, 1(2), 107-142.

Podsakoff, P. M., MacKenzie, S. B., Jeong-Yeon, L., \& Podsakoff, N. P. (2003). Common method biases in behavioral research: A critical review of the literature and recommended remedies. Journal of Applied Psychology, 88(5), 879-903. 
Pouya, A. R., Azar, A., Moshbaki, A., \& Jafarnejad, A. (2010). The relationship between production decision of leadership style and innovation in production in production strategies. Daneshvar (Raftar) Management and Achievement, 44, 443-460.

Purvanova, R. K., Bono, J. E., \& Dzieweczynski, J. (2006). Transformational leadership, job characteristics, and organizational citizenship performance. Human Performance, 19(1), 1-22.

Quinn, R. W., \& Dutton, J. E. (2005). Coordination as energy-in-conversation. Academy of Management Review, 30, 36-57.

Ramsey, R. P., \& Sohi, R. S. (1997). Listening to your customers: The impact of perceived salesperson listening behavior on relationship outcomes. Journal of the Academy of Marketing Sciences, 25(2), 127-137.

Reuvers, M., van Engen, M. L., Vinkenburg, C. J., \& Wilson-Evered, E. (2008). Transformational leadership and innovative work behavior: Exploring the relevance of gender differences. Creativity and Innovation Management, 17, 227-244.

Roberts, L. M. (2006). Shifting the lens on organizational life: The added value of positive scholarship. Academy of Management Review, 31(2), 292-305.

Rogers, C. (1961). On becoming a person: A therapist's view of psychotherapy. New York: Houghton Mifflin.

Sanjaghi, M. E., Farehi Buzanjani, B., Hosseini Sarkhosh, M., \& Haji Shafiee, J. (2011). The mediating role of adaptability culture in the relationship between transformational leadership and organizational innovation. Management Improvement, 3, 122-139. (In Persian).

Schein, E. H. (1985). Organizational culture and leadership. San Francisco: Jossey-Bass Publishers.

Schein, E. H., \& Bennis, W. (1965). Personal and organizational change through group methods. New York: Wiley.

Scott, S. G., \& Bruce, R. A. (1994). Determinants of innovative behavior: A path model of individual innovation in the workplace. Academy of Management Journal, 37, 580-607.

Seltzer, J., Numerof, R. E., \& Bass, B. M. (1989). Transformational leadership: Is it a source of more or less burnout or stress? Journal of Health and Human Resources Administration, 12, 174-185.

Shamir, B. (1991). The charismatic relationship: Alternative explanations and predictions. The Leadership Quarterly, 2, 81-104.

Shamir, B., House, R. J., \& Arthur, M. B. (1993). The motivational effects of charismatic leadership: A self-concept based theory. Organizational Science, 4, 577-594.

Shin, S. J., \& Zhou, J. (2003). Transformational leadership, conservation, and creativity: Evidence from Korea. Academy of Management Journal, 46, 703-714.

Siu, O. L., Spector, P. E., \& Cooper, C. L. (2006). A three-phase study to develop and validate a Chinese coping strategies scale in Greater China. Personality and Individual Differences, 41(3), 537-548.

Siu, O. L., Lu, C. Q., \& Spector, P. E. (2007). Employees' well-being in Greater China: The direct and moderating effects of general self-efficacy. Applied Psychology: An International Review, 56(2), 288-301.

Sivanathan, N., Arnold, K. A., Turner, N., \& Barling, J. (2004). Leading well: Transformational leadership and well-being. In A. Linley \& S. Joseph (Eds.), Positive psychology in practice (pp. 241-255). Hoboken, NJ: Wiley.

Škerlavaj, M., Štemberger, M. I., Škrinjar, R., \& Dimovski, V. (2007). Organizational learning culturethe missing link between business process change and organizational performance. International Journal of Production Economics, 106(2), 346-367.

Skinner, C., \& Spurgeon, P. (2005). Valuing empathy and emotional intelligence in health leadership: A study of empathy, leadership behavior and outcome effectiveness. Health Services Management Research, 18(1), 1-12.

Sosik, J. J., Kahai, S. S., \& Avolio, B. J. (1998). Transformational leadership and dimensions of creativity: Motivating idea generation in computer-mediated groups. Creativity Research Journal, 11(2), 11-121.

Sparks, K., Faragher, B., \& Cooper, C. L. (2001). Well-being and occupational health in the 21st century workplace. Journal of Occupational and Organizational Psychology, 74(4), 489-509.

Spector, P. E. (2006). Method variance in organizational research: Truth or urban legend? Organizational Research Methods, 9, 221-232.

Stevens, C. U., D'Intino, R. S., \& Victor, B. (1995). The moral quandary of transformational leadership: Change for whom? Research in Organizational Change and Development, 8, 123-143.

Tagger, S. (2002). Individual creativity and group ability to utilize individual creative resources: A multilevel model. Academy of Management Journal, 45, 315-330. 
Thompson, M., \& Kahnweiler, W. (2002). An exploratory investigation of learning culture theory and employee participation in decision making. Human Resource Development Quarterly, 13, 271288.

Turner, N., Barling, J., \& Zacharatos, A. (2002). Positive psychology at work. In C. R. Snyder \& S. J. Lopez (Eds.), Handbook of positive psychology (pp. 715-728). New York: Oxford University Press.

Tynan, R. (2005). The effects of threat sensitivity and face giving on dyadic psychological safety and upward communication. Journal of Applied Social Psychology, 35, 223-247.

Vera, D., \& Crossan, M. (2004). Strategic leadership and organizational learning. Academy of Management Review, 29, 222-240.

Wang, P., \& Rode, J. C. (2010). Transformational leadership and follower creativity: The moderating effects of identification with leader and organizational climate. Human Relations, 63, 1105-1128.

Warr, P. (1999). Well-being and the workplace. In D. Kahneman, E. Diener, \& N. Schwarz (Eds.), Wellbeing: The foundations of hedonic psychology (pp. 392-412). New York: Russell Sage Foundation.

Warr, P. (2006). Differential activation of judgments in employee well-being. Journal of Occupational and Organizational Psychology, 79(2), 225-244.

West, M. A. (1990). The social psychology of innovation in groups. In M. A. West \& J. L. Farr (Eds.), Innovation and creativity at work: Psychological and organizational strategies. Chichester: Wiley.

West, M. A. (2002). Sparkling fountains or stagnant ponds: An integrative model of creativity and innovation implementation in work groups. Applied Psychology: An International Review, 51, 355-424.

West, M. A., \& Anderson, N. (1996). Innovation in top management teams. Journal of Applied Psychology, 81, 680-693.

Wilson-Evered, E., Härtel, C. E. J., \& Neale, M. (2001). A longitudinal study of workgroup innovation: The importance of transformational leadership. In M. D. Fottler, G. T. Savage, \& J. D. Blair (Eds.), Advances in health care management (Vol. 2, pp. 315-340). Amsterdam: Elsevier Science.

Wilson-Evered, E., Härtel, C. E. H., \& Neale, M. (2004). Leadership and innovation surfacing synergies among theories and constructs. In A. Ghobadian, N. O'Regan, D. Gallear, \& H. Viney (Eds.), Strategy and performance: Achieving competitive advantage in the global market place. Basingstoke: Palgrave Macmillan.

Woodman, R. W., Sawyer, J. E., \& Griffin, R. W. (1993). Toward a theory of organizational creativity. Academy of Management Review, 18, 293-321.

Wright, T. A., \& Staw, B. M. (1999). Affect and favorable work outcomes two longitudinal tests of the happy-productive worker thesis. Journal of Organizational Behavior, 20(1), 1-23.

Wu, M., Huang, X., Xu, J., Yan, H., \& Shi, K. (2007). Comparative study of transactional, transformational, and paternalistic leadership behaviors and leadership mechanism. Science Research Management, 28(3), 168-176. (in Chinese).

Yang, B. (2003). Identifying valid and reliable measures for dimensions of a learning culture. Advances in Developing Human Resources, 5, 152-161.

Yukl, G. (1998). Leadership in organizations. Upper Saddle River, NJ: Prentice-Hall.

Yukl, G. (1999). An evaluation of conceptual weakness in transformational and charismatic leadership theories. The Leadership Quarterly, 10, 285-305. 